\title{
PEDAGOGIA E AS INFLUÊNCIAS DAS TECNOLOGIA DIGITAIS
}

\author{
Ciane Pinto Pantoja \\ Professora Tutora Externa: Alexandra Magalhães Frighetto \\ Centro Universitário Leonardo Vinci - UNIASSELVI \\ Licenciatura em Pedagogia (PED 1502) Projeto de Ensino
}

$15 / 10 / 2019$

\section{RESUMO}

O objetivo deste trabalho acadêmico, foi identificar a utilização e a influencias das tecnologias no ensino aprendizagem. Demostrar as dificuldades barreiras que os professores encontram neste novo caminho. De modo que as utilizações das tecnologias são de grande importância para o desenvolvimento e aprendizagem dos alunos. É necessário a inclusão de novas tecnologias pois a mesma cresce em ritmo acelerado onde somos bombardeados por informações a todo o momento, como recurso facilitador no processo de ensino aprendizagem, também se faz necessário a formação e preparação dos professores, para assim utilizar essas tecnologias em favor dos alunos em sala, a partir da inclusão deste recurso as aulas ficam muito mais atrativas e interessante para todos, os alunos gostam de inovação e a tecnologia é ferramenta que eles mais utilizam na atualidade. Investir na forma docente, para que os professores se tornem capazes de adequar as suas metodologias de ensino as mudanças tecnológicas, para muitos professores essas tecnologias é um método de ensino pouco utilizado, já tem outros professores que fazem uso do recurso da tecnologia quase cem por cento além de facilitar é prático, interessante, dinâmica e torna a aula diferenciada, possibilita a discursão de temas em sala, reduz a evasão escola, estimula o autodidatismo e sem dúvida a tecnologia favorece a interação entre alunos ao fazer atividades em pares ou grupos, a internet por exemplo permite que todos expressam seu conhecimentos e deem opiniões o que mostra a experiência prévia do aluno.

Palavras-Chaves: Tecnologia e Educação.

\section{INTRODUÇÃO}

Com os avanços tecnológicos e, os acessos às informações, se faz necessário o uso das tecnologias na sala de aula, pois os mesmos já estão presentes no cotidiano dos alunos. Seja nas redes sociais, em jogos on-line ou em blogs, as tecnologias se fazem presente, com isso as escolas passam por momentos de incertezas, com o que se deve fazer a respeito dos aparelhos eletrônicos, como celulares, tabletes e notebooks. Como manter uma geração em que todos já estão conectados com a tecnologia, se o professor por sua vez, tem apenas disponíveis os recursos como, a lousa e o 
giz. Com isso vem os desafios aos professores que precisam vencer as barreiras da falta de motivação de alguns alunos e com a falta destes recursos.

O uso das "Tics" vem revolucionando a educação, pois ao usar estes recursos planejadamente, o professor estará disponibilizando aos alunos uma nova forma de aprender, os instigando a pesquisar e descobrir inúmeras novidades no mundo educacional.

As tecnologias vieram pra ficar e, para que todo esse processo de inserção das tecnologias digitais no ensino, há a necessidade dos professores buscarem a qualificação, o conhecimento e o domínio destas ferramentas, ter o conhecimento do potencial tecnológico, reconhecer a sua importância no ensino aprendizagem, devem estar motivados a usar da melhor maneira possível, e estar confiantes e preparados para poderem se posicionar frente as inovações com criatividade e desenvoltura, aplicando-as a sua pratica pedagógica, por este motivo é fundamental que os professores tenham domínio as habilidades exigidas para trabalhar com os alunos, resolver problemas e tomadas de decisões, boa comunicação e trabalhos colaborativos.

Além da grande necessidade e da boa vontade da equipe gestora de manter a escola com suas informatização e tecnologia atualizadas sempre surgem certas dificuldades de aquisição seja financeira ou questões burocráticas, a verba nas escolas é uma questão sempre de limitações então é como se a verba oferecida não fosse suficiente para atender todas as necessidades daquela comunidade então esse é um dos desafios a falta de verba e estrutura física, muitas vezes quando se tem verba para ampliar o uso de tecnologias falta espaço físico nas escolas por isso é fundamental encontrar soluções para solucionar estes problemas e alcançar objetivos é de suma importância que gestão escola e corpo docente trabalhem em perfeita sincronia. (TAJRA, 2000)

\section{A IMPORTÂNCIA DA TECNOLOGIA NA EDUCAÇÃO}

A tecnologia já mudou muitas coisas em nossas vidas, a forma como a gente produz, como consome, interagem até mesmo como estudamos.

A tecnologia está chegando em todas as escolas, alguns anos atrás poderíamos contar quais das escolas em nossas cidades tinham laboratório de informática internet então era como um evento hoje a questão é bem diferente hoje todas as escolas seja ela Estadual ou Municipal possuem internet, não quer dizer que seja somente para benefício do aluno como aprendizado, mais também é uma necessidade para o funcionamento da escola como um todo por tanto é uma realidade está 
impactando dentro do nosso cotidiano, podemos até dizer que o século XXI é marcado pelo avanço das tecnologias e claro quanto mais tecnologias mais opções e condições de escolhas teremos em muitas ares ao nosso redor seja do alimentício, estética, medicamento, cirurgia até a educação e com certeza essas mudanças modifica muito nossa vidas, um grande exemplo: é o celular imagine quantas funcionalidades agrega um celular, muitas vezes o que menos usamos nele é tradicional ligação que seria a principal finalidade deste aparelho aos anos atrás hoje conseguimos estudar, responder provas e até mesmo trabalho com esse aparelho.

Mais o objetivo principal é falarmos deste avanço na área educacional, o nosso modelo educacional nunca foi ineficiente, mais hoje temos muito mais possibilidades trazidas com a educação e avanços tecnológicos professores e alunos temos hoje a oportunidade de tirar proveito se apropriar de todo esse conhecimento que a tics oferecer bem mais para seus alunos como aula mais dinâmica e divertida, realizando trabalhos em grupo, prendendo a atenção do aluno, realizando pesquisas com auxílio da internet, muito são as vantagens dos usos das tics que é nossa grande aliada em busca do tão sonhado conhecimento, pois os recurso digitais podem ser introduzidos nas aula ade várias maneiras, pode ser um vídeo de algum tema que iremos abordar na aula, pode ser um jogo de perguntas e respostas que também lhe oferece meios de avaliar o aluno inúmeras são as possibilidades e descoberta trazendo novas perspectivas e demandas para a escola.

A pratica é para tentar alcançar o melhor entendimento possível nesse aluno, que ele tenha a capacidade de desenvolver novos conhecimentos e alcançar objetivos através desse suporte tecnológico que ele venha receber.

Como todo conteúdo tem seus dois lados o aprendizado, conhecimento, mais também existe os riscos que corremos ao não uso correto dessa ferramenta identificar o que é uma fonte segura para ajudar este aluno a ter uma visão crítica do que circula na internet como por exemplo: exposição a conteúdos impróprios, racismo, pornografia, violência etc.

Nem sempre admitimos o quanto somo dependente da tal tecnologia, mais existe a necessidade de nos mantermos sempre bem informados e claro é mais rápido fazermos uma pesquisa na internet do que lermos um livro, é mais rápido e vantajoso pesquisar em site de notícias do que esperar o jornal do dia na tv, então é quase impossível a tics não entrar no nosso dia-a-dia por inúmeras vezes, assim corre na escola, no trabalho, em casa mesmo existindo muitas dificuldades na escola como quantidade de equipamento insuficiente, falta de pessoas especializadas em programas e tics, mais claro esses problemas ainda são contornáveis no meio educacional. 


\subsection{FORMAÇÃO DE PROFESSORES PARA O USO DAS TECNOLOGIAS}

Mudou a forma de como as pessoas se comunicam, mudou a forma de como nós trabalhamos, mudou a forma de como o professor faz seu planejamento, mudou a forma de como esse professor se expressam, a velocidades das coisas acontecendo ao nosso redor é tão grande que muitas vezes nem conseguimos acompanhar tudo aquilo que deveríamos, as formas mais acessíveis de preparar o professor para o uso das tecnologias seria apresentando instrumento e ferramentas, treinado e dando recurso, muitos professores estão realmente preparados para este mundo de tecnologias outros já não tem a mesma oportunidade ou facilidades neste aprendizado e penso que se houver dificuldades podem interagir professor e aluno, aluno e professor e assim trocar novos conhecimentos a tecnologia claro não vai transformar professor e aluno, aluno e professor em poucas aulas mais com certeza ira potencializar o conhecimento de ambos sobre a tics, inovação na educação é indispensável, se não houver foco nas tecnologias da educação as próximas gerações enfrentaram dificuldades no aprendizado pois muitos alunos de hoje serão os professores de amanhã e é muito importante que desenvolvam bons conhecimentos para que possa transferir no amanhã, nos dias de hoje ter educação de qualidade significa estimular a tecnologia que serve para dá suporte ao professor e ampliar o conhecimento dos alunos, mais isso irá acontecer se os professores tiverem formação de qualidade principalmente aqueles da rede pública a tecnologia produz em todos os setores aumento dos níveis de produtividade se investir no professor porque nós como alunos nosso principal fonte de conhecimento em sala de aula é o professor, então a uma necessidade muito grande desse profissional está preparado para passar conhecimento é importante para o futuro de um pais que suas crianças recebam conhecimento ampliado, adequado e rico de valores, isso não fluência somente uma criança, um professor isso fluência uma nação, professor vai muito além da área educacional, vai até a segurança a saúde pública então cada professor que não tem a oportunidade de se qualificar e está sempre atualizado não é só ele quem perdi são os alunos conhecimento tira as pessoas da linha de pobreza, então penso que o prejuízo é muito grande.

As instituições privadas vêm fazendo uso de ferramentas tecnológicas de maneira gradual e sistemática, auxiliando o processo de ensino aprendizagem. As escolas da rede pública têm encontrado diversos desafios para a implantação e o uso desses recursos. Porém, a implementação do governo brasileiro do projeto UCA (Um computador por aluno) apresentou alguns benefícios para o ensino público. O projeto, que teve início em 2007, tem 
por objetivo facilitar o processo de ensino e aprendizagem, ofertando um computador para cada educador e aluno das escolas públicas de Educação Básica (MEC, 2010).

Mas quais os principais desafios encontrados pelo professor:

Primeiro desafio segundo blog: motivos que relata o blog é que os professores argumentam que a falta de tempo para atividades pessoais do professor, em geral justificam sua baixa remuneração, devido está situação eles preferem assumir outras funções ou até mesmo trabalhar por vários turnos.

No segundo desafio segundo o blog: lidar com diferentes perfis ao longo de toda trajetória profissional:

O professor deve lidar com alunos de variados estilos: desinteressados, desmotivados, despreocupados, irresponsáveis, tímidos, distraídos, impacientes etc. Deve, contudo, saber instigar a curiosidade de cada um deles ao longo de toda sua trajetória profissional e motivá-los, respeitando as particularidades de cada um, para que suas turmas tenham maior engajamento na realização de atividades e maior participação durante as aulas.

Terceiro desafio segundo pesquisa do blog: identificar, compreender e reparar as dificuldades encontradas pelos alunos: de forma a ser um bom guia para o conhecimento, o professor deve saber identificar, compreender e auxiliar seus alunos em relação as suas dificuldades, pois elas representam grandes desmotivadores e contribuem para o baixo rendimento escolar. Assim saber exatamente onde os alunos estão com problemas, facilitar no direcionamento e na realização de intervenção pedagógicas e, consequentemente no aprimoramento do processo pedagógico.

Quarto desafio segundo pesquisa do blog: realizar atividades diversas:

Cada aluno é único e apresenta competências e dificuldades especificas. O educador também deve lecionar os conteúdos a serem passados por meio de atividades variadas, atendendo às necessidades de todos.

Pensando além do desenvolvimento cognitivo dos alunos, também é fundamental que o professor proponha atividades para trabalhar as competências socioeconômicas em sala de aula. Essas competências são tão importantes que inclusive são previstas pela Base Nacional Comum Curricular (BNCC), que defende a formação integral do aluno.

Quinto desafio segundo blog: regulando a prática do celular: o uso do celular em sala de aula: é um assunto bem recorrente e merece bastante atenção. $\mathrm{O}$ uso pedagógico de aparelhos eletrônicos pode contribuir de maneira efetiva para a motivação e aprendizagem dos alunos e também é mencionado no documento da BNCC. O maior desafio nesse contexto é fazer com que os professores aprendam a administrar essa tecnologia de maneira mais assertiva. Informações e imagens coletadas do blog somo par.com.

\section{INSERÇÃO DAS TECNOLOGIAS NA EDUCAÇÃO}

\subsection{COMO INSERIR AS TECNOLOGIAS NA EDUCAÇÃO.}

O fato de se tratar de um professor não significa que ele não terá duvidas ou dificuldades para inserir as tecnologias em seu conteúdo didáticos no dia-a-dia em sala de aula.

O fato é que a tics é uma grande ferramenta e deve ser estimulada o seu uso na educação a preocupação não é quando seria mais como seria este uso? De que forma? Quais seriam as vantagens? São muitas as perguntas. 
O certo é que a escola não pode repetir o que os alunos já sabem, entregar algo pronto ou colocar joguinhos educativos para eles e isso vai de uma simples pesquisa até mesmo uma interpretação de texto ou até uma discussão políticas, na minha opinião o professor tem que ensinar o aluno a transformar o que ele tem em mãos, a tecnologia é uma linguagem e os alunos precisam aprender o código dessa linguagem para que eles não dominam e para isso dependem e muito do auxílio de um profissional capacitado até porque quem não se adequar, adaptar se a esta tecnologia num futuro bem próximo estará fora inclusive do mercado de trabalho os quais está sendo todo informatizado, com estes avanços a mão de obra reduz por que a tecnologia consegui suprir muito nessa redução, vou citar um bom exemplo aqui para termos conhecimento do tamanho que a tecnologia avançou nos últimos anos, o nosso smart phone é mais avançado no sentido tecnologia do que o computador que gerenciou a ida do homem á lua em 1969 então vejamos o potencial que carregamos no nosso dia-a-dia.

Onde aplicar as tecnologias nas aulas, acredito que não se escolhe qual mateia se aplica entendo que a tecnologia deverá estar presente em todas as aulas de todas as matérias de alguma forma mesmo sendo numa citação.

\section{FIGURA 2: ALUNOS INTERAGINDO COM AS TECNOLOGIAS}

\section{Foto: Shutterstock}

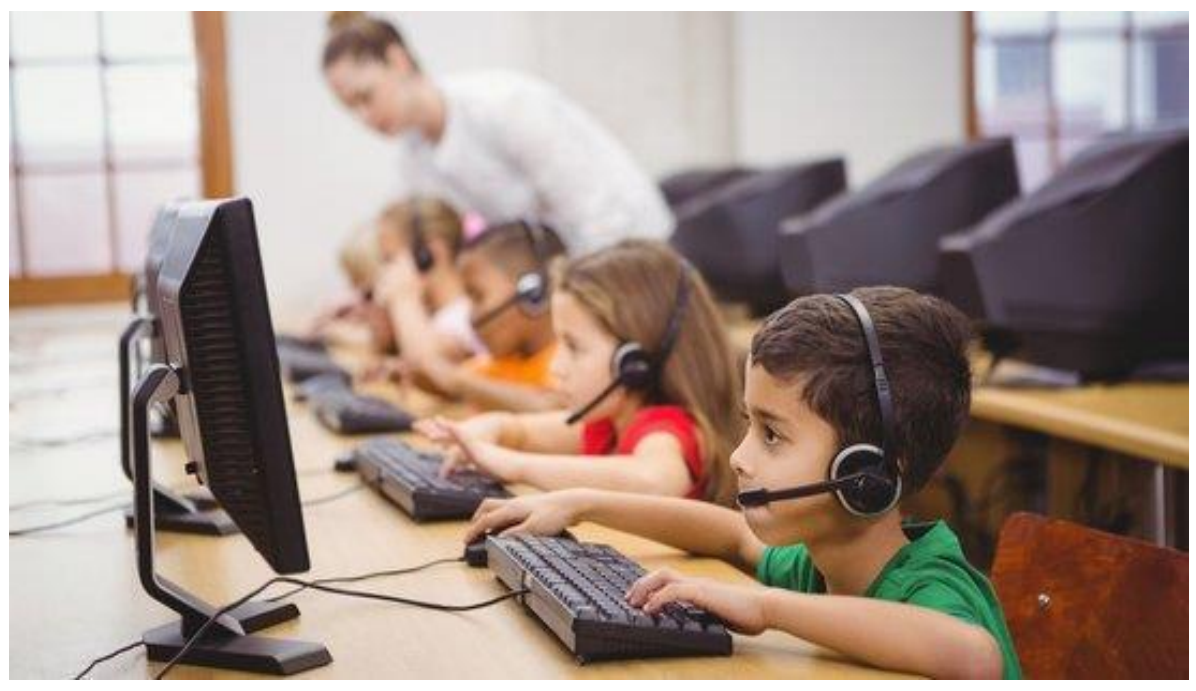

Está imagem mostra muito bem a dedicação do professor em aula de informática, favorecendo o aprendizado da tecnologia nos anos iniciais é um excelente recurso didático da educação infantil e sem dúvida é uma aula muito esperada pelos pequenos, a tecnologia se tornou 
um suporte para aulas e para o professor devido ser um aprendizado diferenciado ajuda a sair um pouco da velha rotina de escrita e sala de aula, em muitas escola existem laboratórios de informática, sala de TV, é muito inovador para eles (alunos) fazer uma pesquisa online, assistir algum vídeo ou documentário em Datashow.

\section{FIGURA 3: FERRAMENTAS TECNOLÓGICAS DO CONTEXTO ESCOLAR}

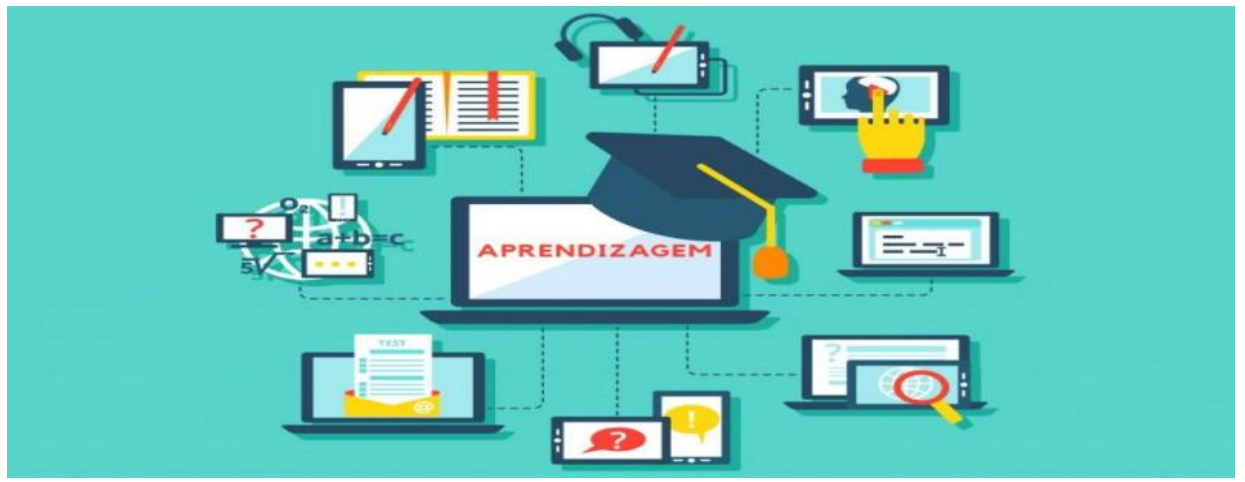

Fonte: blog cantinho do professor.com.br

O blog cantinho do professor fala exatamente da pedagogia e as tecnologias assim como mostra a imagem acima, diversas são as ferramentas tecnológicas nos dias atuais, em todos os campos seja educação, saúde, segurança etc.

Para a educação, a tecnologia abre um leque de oportunidades e ferramentas de trabalho e recursos para os estudantes, professores que os levam a aprimorar e elevar seus conhecimentos devido aos benefícios que a tecnologia traz pois a cada dia novos avanços surgem na área facilitando o trabalho e o dia-a-dia de cada um de nós.

De acordo com Mercado (2002 p.23):

\footnotetext{
Ajudar os alunos a estabelecerem um elo entre os conhecimentos acadêmicos com os adquiridos e vivenciados, ocorrendo uma troca de ideias e experiências, em que o professor, em muitos casos, se coloca na posição do aluno, aprendendo com a experiência desde (MERCADO, 2002, p. 23).
}

Sem dúvida é um elo mesmo entre professor e aluno, são trocas de conhecimento e informações enriquecedoras para ambos e com certeza todos só tem a ganhar com experiências seja tecnologias como didáticas quando se trata de conhecimento tudo é importante. Os alunos apreendem muito com informação e orientação passada pelo professor em sala de aula o professor tem uma bagagem e conhecimento suficiente para auxiliar sua turma e conseguir identificar o grau de dificuldade de cada aluno. 


\section{RESULTADOS E DISCUSSÕES}

Falar de Pedagogia e conteúdo de anos iniciais atualmente exige muito do professor devido à quantidade de informações que são dadas. Os vários conceitos abordados e a diversidade de conteúdos levam ao desinteresse a respeito dos temas por isso o uso das (tics) poderia melhorar essa compreensão e esse desejo de entender melhor cada disciplina e sem dúvida os professores utilizam a seu favor este recurso para atrair a atenção do aluno, o costume de papel, caneta, lousa, já não é a mesma na rotina dos alunos uma vez que a tecnologia já está inserida em diversas esferas de suas vidas como o uso do aparelho celular essa mobilidade permitiu acesso a informação a qualquer hora e lugar então porque não explorar essas ferramentas para a educação e é nesse campo que a tecnologia já se faz presente em inúmeras atividades que são incluídas nos planos de aulas com os recursos tecnológicos e esse benefício agrega muito na didática no desenvolvimento é importante pensar que as novas tecnologias pode promover a autonomia do aluno e claro temos que incentiválos a fazer o uso responsável.

No entanto, o acesso a um ensino de qualidade ainda é privilégio de uma pequena parcela da nossa sociedade. No que diz respeito aos ensinos básico, fundamental e médio, a realidade é assustadora; crianças, jovens e adultos de classes menos favorecidas, por diversos motivos socioeconômicos, desvinculam-se de uma instituição de ensino e muitas vezes ficam fora da faixa etária apropriada para o nível de escolaridade em que se encontram.

Aliada a isso, existe uma estrutura política em que os incentivos à prática docente não são dos melhores, principalmente nas instituições públicas, que ainda mantêm muitos dos seus docentes com concepções, ideias e atitudes tradicionais que, na maioria das vezes não despertam nos alunos o interesse em aprender, aumentando ainda mais o distanciamento escolar. Isso contribui bastante para o acesso tão restrito de jovens egressos de escolas públicas ao ensino superior no nosso país.

Mercado (2002) nos diz que a formação continuada pode permitir condições para o professor construir conhecimento sobre as tecnologias, entender por que e como integrar estas na sua prática pedagógica e ser capaz de superar entraves administrativos e pedagógicos. Os benefícios da formação continuada podem favorecer o professor e os alunos, já que possibilitam a transição de 
um sistema fragmentado de ensino para uma abordagem integradora voltada para a resolução de problemas específicos do interesse de cada aluno.

Sendo assim, ressalto a importância de discutir, repensar e reformular a formação de professores, para que estes sejam capazes de fazer uso desse recurso tão importante em sala de aula, que é a tecnologia. Com investimento na formação inicial e continuada, os docentes podem ser capazes de adequar as estratégias de ensino às mudanças tecnológicas. Além disso, é importante ressaltar que a formação docente é incessante, ou seja, não tem fim, e acontece todos os dias, em cada sala de aula e em contato com cada indivíduo.

Não basta utilizar apenas recursos tecnológicos, porque o que pode acontecer será de ter aulas modernas com currículos ultrapassados, precisa-se também uma nova restruturação por parte das Secretárias de Educação, com uma nova postura para que o ensino se torne uma forma que todas as pessoas possam lutar por melhores condições de vida.

Devido ao fato de muitos professores atuarem nos três períodos o que dificulta terem tempo para aprender esses novos recursos, e uma questão complicada pode ser a desvalorização que eles vêm sofrendo perante a sociedade e a falta de respeito por parte de muitos alunos.

O blog Somospar possui uma conclusão a respeito desses desafios do educador, porem argumento aqui meu pensamento a respeito dos desafios. São muitos os desafios para o professor e tamanha é sua responsabilidade diante de tanta inovação e práticas diferenciadas, o professor deve trabalhar favorecendo desenvolvimento do aluno de maneira efetiva e diante de tanta responsabilidade e comprometimento deve ficar atento com suas falas em sala para não desmotivar seu aluno pois um dos objetivos é bem o inverso motiva-los até porque não sabemos o que esse aluno passou para chegar até a sala de aula naquele determinado dia, conduzir a aula sempre com dedicação e sempre se mostrar ser um bom aliado para o conhecimento e desenvolvimento, sem falar que é notável a importância do uso das tecnologias em sala de aula e a discussão sobre esta para a sociedade, o uso desta ferramenta deve ser de forma consciente inclusive este mais um dos papeis do docente orientador passar tais informações para os alunos, é muito importante destacar que os alunos são mais facilmente adeptos aos recursos tecnológicos, já muitos dos professores sentem maior dificuldades para se adaptar ao uso de tecnologias seja por falta de tempo, incentivo ou formação.

\section{CONCLUSÃO}


A pesquisa buscou-se entender as dificuldades encontradas para inserir a tecnologia como ferramenta de ensino, melhorando o ensino aprendizagem. Diante disso, após analisar as obras escolhidas, percebe-se que a tecnologia por si só não resolve os problemas, mas é necessário que haja a elaboração de uma metodologia de ensino que consiga congregar a tecnologia em sala de aula. Essa metodologia precisa ser inovadora tanto para acompanhar a evolução da tecnologia quanto para extrair o máximo dos alunos. Além disso, é necessário que o professor tenha um planejamento bem elaborado que direcione o aluno a alcançar os objetivos propostos para a aula, sem que ele fique ocioso ou que navegue por assuntos que não estejam relacionados a aula. Verificou-se também que os professores, muitas vezes, não utilizam a tecnologia com mais frequência devido ao medo, ao despreparo e ao desconhecimento das tecnologias. É necessário que haja preparo dos professores para o manuseio das tecnologias, para que eles possam extrair o máximo delas.

E isso, só será possível, principalmente e exclusivamente através da formação e da capacitação dos professores tanto para o manuseio quanto para a inserção em sala de aula. Tanto a falta de capacitação quanto a falta de utilização das tecnologias trazem grandes prejuízos para os alunos. Quanto a essa formação, cabe aos gestores escolares buscarem parceiras juntamente com as secretarias de educação para promover essa formação de forma a incentivar e ajudar os professores tanto a aprender quanto a utilizar a tecnologia em sala de aula.

A tecnologia proporciona diversas possibilidades para a sua utilização, basta uma metodologia e um planejamento adequado, que seja inovação e acompanhe a evolução da tecnologia e que auxilie os alunos na busca de informações para a produção de conhecimento de forma plena. Conclui-se então que ela, traz grandes benefícios para a educação e contribui para o desenvolvimento pleno do educando, principalmente no desenvolvimento de habilidades, além de facilitar a busca por novos conhecimentos, melhora a participação e interação em sala de aula e proporciona uma aula mais dinâmica, participativa e rica em informações sem dúvidas os alunos tem melhor rendimento com uma aula e claro não é só o aluno que pode tirar proveito disso, o trabalho do professor se torna muito mais rápido, eficiente e prático, adotar métodos tecnológico nas aulas amplia conhecimento gera aperfeiçoamento da sua pratica pedagógica e irá melhorar todo o processo de aprendizagem é muito importante que o professor seja além de facilitador, mas se torne um canalizador para novas descobertas. 


\section{REFERÊNCIAS}

MEC - Ministério da Educação. Computadores prometem aulas divertidas e melhor aprendizado, 2010. Disponível em: <

http://portal.mec.gov.br/component/tags/tag/34746> Acesso: 10 de Maio de 2019.

MERCADO, Luis Paulo Leopoldo. (Org.). Novas tecnologias na educação: Reflexões sobre a prática. Maceió. EDUFAL, 2002.

https://novaescola.org.br/conteudo/4671/tres-formas-de-inserir-a-tecnologia-em-sala-de-aula-nodia-a-dia

https://www.somospar.com.br/maiores-desafios-do-professor/

http://www.cantinhodoprofessor.com.br/a-importancia-da-tecnologia-para-a-pratica-docente/

Livro Educação e tecnologias Uniasselvi 2017 TAJRA 2000 = biblioteca digital 